Article

\title{
Coupling Coordination Evaluation between Population and Land Urbanization in Ha-Chang Urban Agglomeration
}

\author{
Huilian Han and Hui Li * \\ Northeast Asian Studies College, Jilin University, No. 2699 Qianjin Street, Changchun 130012, China; \\ hanhl17@mails.jlu.edu.cn \\ * Correspondence: li_hui@jlu.edu.cn
}

Received: 3 November 2019; Accepted: 31 December 2019; Published: 2 January 2020

\begin{abstract}
As the major form of urbanization, urban agglomeration integrates urban resources, adjusts industrial structure, narrows the gap between urban and rural areas, enhances urban function, strengthens urban competitiveness, and promotes the strategy of regional sustainable development. Based on the panel data of 10 cities in Ha-Chang urban agglomeration from 2000 to 2014, this paper establishes an evaluation index-system of population and land urbanization quality level, and analyzes the coordination degree, spatial heterogeneity, and spatiotemporal evolution of urbanization, through using the methods of range standardization, entropy weight model, and coupling coordination models. Results show that the quality of population and land urbanization was increasing gradually during the study period. However, the coordination degree between population and land urbanization rate is decreasing. The comprehensive level of population and land urbanization increasing yearly, from low-level coupling coordination reverse to high-level coupling stage. The quality differences between the population and land urbanization of the ten cities of the Ha-Chang urban agglomeration are significant. The radiation function of large-sized cities and the regulation of medium-sized cities are not strong, and the coordination degree of small-sized cities is low. In view of the coordinated status of the Ha-Chang urban agglomeration, differently size cities should propose corresponding urbanization development strategies to enhance the main function of the urban agglomeration.
\end{abstract}

Keywords: Ha-Chang urban agglomeration; population urbanization; land urbanization; coupling coordination degree

\section{Introduction}

Urbanization is an important mechanism for China's steady growth and structural adjustment as well as a necessary path for social and economic transformation. Cities are important space carriers of industrialization and urbanization. Hence, the key sustainable development in China lies in the sustainable development of cities [1]. Cities are not an isolated and closed system, they are related closely to adjacent areas and towns, and they constantly exchange materials and capabilities with them in reality. Each city is an important part of regional urban agglomerations, which constitute a relatively complete organic whole [2]. Urbanization is an important physical factor and closely related to urban planning which may support unsustainable outcomes [3]. Urban agglomeration is an urban form which is the comprehensive result of the interaction between various human activities and natural factors [4]. Urban agglomeration involves a considerable number of cities with different natures, types and grades, with one or two oversized cities or megacities as the core of the regional economy, relying on certain natural environment conditions, within a specific geographical area. Urban agglomeration utilizes modern transportation, integrated transport networks and developed information networks; it 
also promotes intrinsic links among urban individuals, thereby constituting a relatively complete urban agglomeration [5]. As major form of urbanization, the urban agglomeration population accounts for $70 \%$ of the urban population in China, and its population and region adopt a point-like development pattern, to form an accumulated spatial layout form. The 19th National Congress of the Communist Party of China emphasized urban agglomeration as the main carrier in building urban patterns with harmonious development in large-, small- and medium-sized cities and realize the citizenization of rural migrants. In an urbanization development in China, problems such as regional differences in urbanization and unbalanced urbanization development are prominent [6]. Urban agglomerations, similar to industrial clusters, are also an important source of national and regional competitiveness. It also participates in global competition and international division of labor to enhance the status of the global economy and plays a significant role for in the sustainable development of the national economy $[7,8]$.

The studies on China's urban agglomeration structure system are about 90 years later than that of Western developed countries, such as Western Europe and North America. The acceleration of urbanization and industrialization in China has given birth to the formation and development of China's urban agglomeration structure system [9]. Currently, the overall development level of China's urban agglomerations remains at the embryonic stage; thus, it is relatively low. The development of urban agglomerations has large spatial differences and low compactness, and the degree of development gradually decreases from east to west $[10,11]$. Since the "11th Five Year Plan" proposed that "urban agglomeration should be the main form to promote urbanization", the theoretical and practical fields have focused more attention on the problem of urban agglomeration than ever before. Large-, medium-, and small-sized cities in urban agglomeration represent the different stages of economic agglomeration. Hence, the population agglomeration effect is also different. Large-sized cities have large populations and the different grade cities have different trends of population growth. Population size and city grade have a close positive correlation because population migration contributes significantly to urbanization. However, the interaction between urbanization and population is not close enough in cities of urban agglomerations [12].

With the continuous spread of cities, high-quality arable land is being lost and fragmentation landscape patterns are increasing, thereby posing threats to sustainable development and regional food security [13]. The change in population size and land use policy in urbanization are important driving forces for the forest spatial changing pattern, which affects the changes in the regional landscape [14]. Hence, urban development must focus on the use of comprehensive resources, handle the coordinated development of population and land urbanization properly, promote a new type of urbanization, and realize the sustainability of urban modernization [15]. Chen Chun [16] explains the connotation of urbanization from four aspects: population, economic, land, and social urbanization. He believed that the healthy urbanization is an urbanization with coordinated development of these four aspects. Among these aspects, population urbanization is at the core and its essence is the transfer of population economic activities to urban areas. Land urbanization is the carrier, which is reflected primarily by the increase in urban built-up areas. The demand for urban agglomerated population for housing, transportation, and public facilities is increasing, thereby forcing land urbanization. Therefore, population urbanization is the most direct cause of land urbanization, and land urbanization is the inevitable result of population urbanization [17]. Urbanization brings a series of problems, such as the coordinated development of rural and urban areas and the coordinated development of population and land [18-20]. Land urbanization and population urbanization are two important components of urbanization, its essence and ultimate objective are to achieve human urbanization; thus, the coordinated development of these two components is the core issue of sustainable development in China [21]. Urban population growth is the major driving factor of urban land expansion [22,23]. The expansion of urban land will convert a large amount of agricultural population into the urban population, thereby leading the government to conduct city-building campaigns that cause government dominating urbanization $[18,24]$. The increase in population density will promote urban construction, 
for example, by increasing urban built-up areas, increasing road area, and improving public facilities, all of which require land resources and regional landscape changes [14]. The population and land use has a important impact on urban form that is closely related to urban planning [3]. The reform of the land system and the household registration system has a significant effect on urbanization and the welfare of residents. Therefore, under strict land control and household registration restrictions, only rural laborers with high human capital will move to cities; however, as the land transfer is allowed or the household registration system is loosened, an increasing amount of rural labor will move to the cities [25]. Traffic congestion has a spatial spillover effect on population urbanization, which has significant heterogeneity on different regions and scales of cites [26]. The land is the only space carrier for urbanization and the promotion of urban construction and urbanization cannot be separated from the elements of land production and land management $[27,28]$. Land cover changes are greater in areas with a high level of industrialization than in other areas and, in such areas, a large amount of land is used for residential and public facility construction [29]. The value of land is evident in economic benefits brought by the conversion of agricultural land due to rapid urbanization [30]. Land management pertains to adjust the relationship between people and land to organize and supervise the utilization of land, protect and use land resources, and improve the benefit of land use. Changes in the landscape pattern of urban land use have become an important indicator of the tension between the socio-economic system and the natural ecosystem [31].

The comprehensive benefit of land use refers to the material output or effective achievement of land input and consumption per unit area in social, economic, ecological, and environmental aspects of regional development [32,33]. Traditional studies have used primarily a single non-agricultural population (or resident population) and urban built-up land area to measure the level of population and land urbanization. The level of urbanization assessed by a single indicator only reflects the speed of urbanization but cannot explain the quality of urbanization [34]. Yu [35] analyzed urbanization from the perspective of population urbanization equilibrium, which refers to the coordination between population development and economic and social development. He found that the coordination is compatible with the carrying capacity of resources and environment, the total population is moderate, the quality of the population is improved comprehensively, the population structure is optimized, and the population distribution is reasonable, and various factors of the population system is developed in a coordinated and balanced manner. Shi [36] analyzed land urbanization and proposed that the efficiency of land use is an important guarantee for the sustainable development of urban agglomerations. The imbalance between land and population urbanization in China because of land finance has caused problems [37]. Therefore, some scholars have studied the coordination between population and land urbanization $[38,39]$. Urbanization constitutes various organism systems such as population, land, economic, and social urbanization, which form an indivisible whole. Hence, only by coordinating the development of each system can the development of the whole system be promoted.

In urbanization, a certain gap commonly exists between the speed of population and land urbanization; however, if the gap between the speed of population and the land urbanization is excessively large, that is, the ratio of urban land use growth to urban population growth is 1.85 , which is much higher than the internationally recognized reasonable threshold of 1.12 [40]; then, city-wide problems will occur and social contradictions will intensify, thereby affecting the construction of a well-off and harmonious society. Hence, urban planners and managers must control the gap within a certain range [34]. The coupling relationship between urban population and land urbanization reflects the coordinated development of cities of different sizes in urban agglomeration. Currently, coordination between population and land urbanization in small- and medium-sized urban agglomerations has been studied frequently, but the coordination of population and land urbanization of Northeast China has been rarely studied. Moreover, the population is the core of urbanization, whereas land is the spatial carrier of urbanization. Their coordinated development is the basis for the government to adjust the population scale, structure, and urban landscape design. It is also an important driving 
force to improve the quality of urbanization and realize the harmonious development of the economy and society.

The Ha-Chang urban agglomeration is an important growth pole for the revitalization and development of old industrial bases in Northeast China. It is an important gateway for the opening of the North, and a pioneer area as the innovation of the institutional mechanisms of old industrial bases, and a green eco-city cluster. The Ha-Chang urban agglomeration is strategically important to accelerate the economic transformation of the Northeast region and enhance its international competitiveness. However, the empirical literature on urbanization in the Ha-Chang urban agglomeration is limited.

Therefore, to reflect the urbanization development status of the Ha-Chang urban agglomeration comprehensively, we use the urbanization rate and quality of population and land to reveal the coordination between population and land urbanization in the current study. In this article, the rate of population urbanization refers to the proportion of the non-agricultural population to the total population, whereas the rate of land urbanization is expressed by the proportion of built-up area to the administrative area. The quality of urbanization is based on the concept of new urbanization. The quality of population urbanization is evaluated using five dimensions: population, economy, public service, cultural life and ecological environment. Land urbanization quality is evaluated using two dimensions: land urbanization input and output.

In this study, we attempt to analyze the urbanization development status from the rate and quality of population and land urbanization coordination stage and identify and understand the level and characteristics of urbanization and its driving forces in the Ha-Chang urban agglomeration and its core cities. In particular, we try to answer four questions:

1. What are the changes and characteristics of the population and land urbanization rate over a period of 14 years?

2. What are the changes and characteristics of the population and land urbanization quality?

3. What are the spatiotemporal characteristics of the population and land urbanization rate coordination?

4. What are the spatiotemporal characteristics of the population and land urbanization quality coordination?

\section{Materials and Methods}

\subsection{Data}

We utilize data from China City Statistical Yearbook (2000-2014) and China Statistical Yearbook for Regional Economy (2000-2014) (shown in Table 1) which contain rich urban information, such as non-agricultural population, proportion of employees in secondary and tertiary industries, per capita disposable income of urban residents, average wage of on-the-job workers, per capita road area, built-up land area, gross domestic product, fiscal revenue, and retail sales of social consumer goods. The relevant indicators of Suihua City are obtained from the Heilongjiang Statistical Yearbook, whereas the indicators of Songyuan City are from the Jilin Province Statistical Yearbook. Although China abolished the agricultural household registration system in 2014, it still plays an important role in the development of urbanization [41]. Therefore, we use the proportion of the non-agricultural population to measure the population and land urbanization rate with the proportion of the built-up area. However, data on the non-agricultural population of urban after 2014 are unavailable because of the changes in the bureau's demographic caliber. Therefore, the sample is studied until 2014. 
Table 1. Research data source.

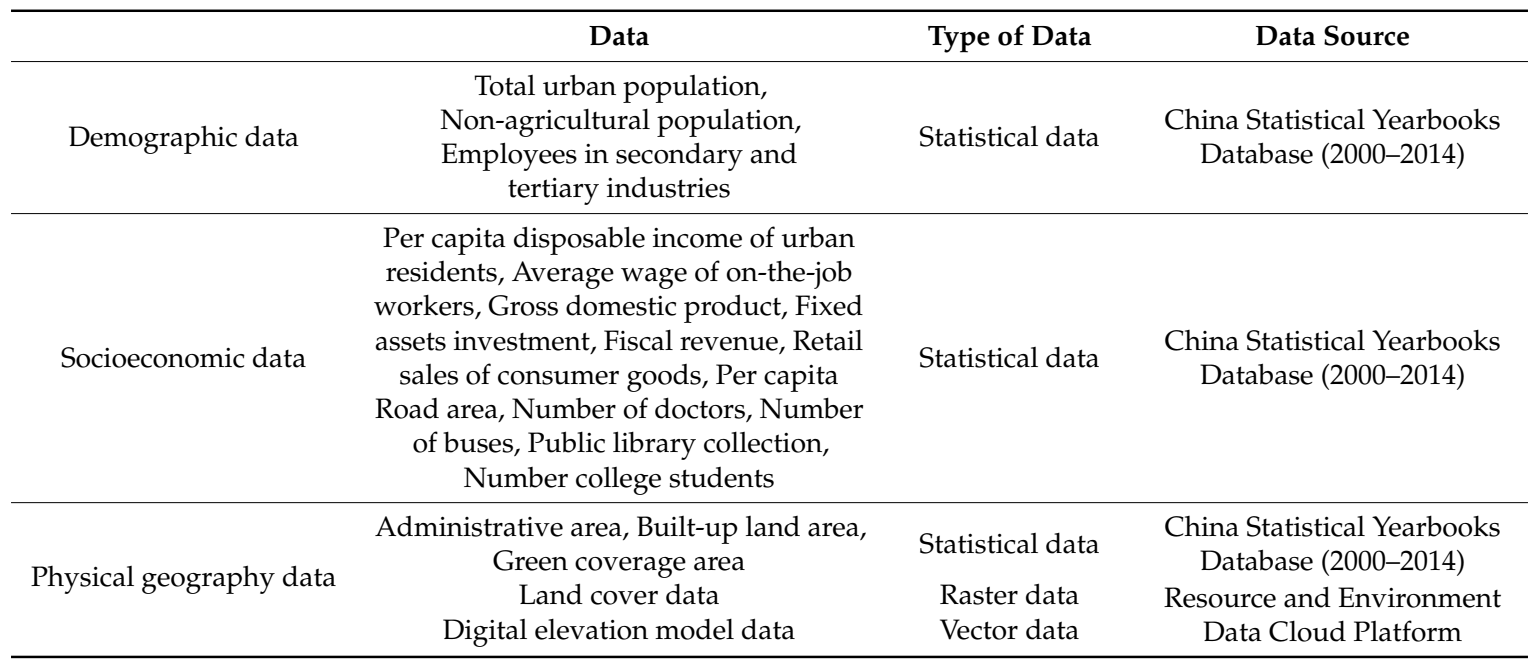

\subsection{Study Areas}

The Ha-Chang urban agglomeration is one of the nine regional urban agglomerations planned by the National Development and Reform Commission. Most indicators of the Ha-Chang urban agglomeration have already met the requirements for becoming a city-aggregation and is one of the ten urban agglomerations developed vigorously by the country [42]. The state has approved nine secondary urban agglomerations in succession. The Ha-Chang urban agglomeration covers ten prefecture-level cities and one autonomous prefecture in Heilongjiang and Jilin Province: Haerbin City, Daqing City, Qiqiha'er City, Suihua City, Mudanjiang City, Changchun City, Jilin Province, Siping City, Liaoyuan City, Songyuan City, and Yanbian Korean Autonomous Prefecture (Figure 1). The administrative area of core cities is about 2.41 million square kilometers. The number of registered households at the end of the year is about 13.516 million, including the non-agricultural population of $3,346,500$ and an agricultural population of 1,016,9900. The administrative area of the Ha-Chang urban agglomeration accounts for about $32.46 \%$ of the total area of the two provinces and the population accounts for $70.24 \%$ of the total of the two provinces. The first, second, and third industries account for $75.99 \%, 89.63 \%$, and $85.86 \%$ of the two provinces, respectively. The areas covered by the Ha-Chang urban agglomeration are the main cities of the two provinces, thereby laying a solid foundation for regional coordinated development. We do not include Yanbian Korean Autonomous Prefecture because of the lack of statistical data. We analyze the coordination population and land urbanization of the ten cities in Ha-Chang urban agglomeration. 


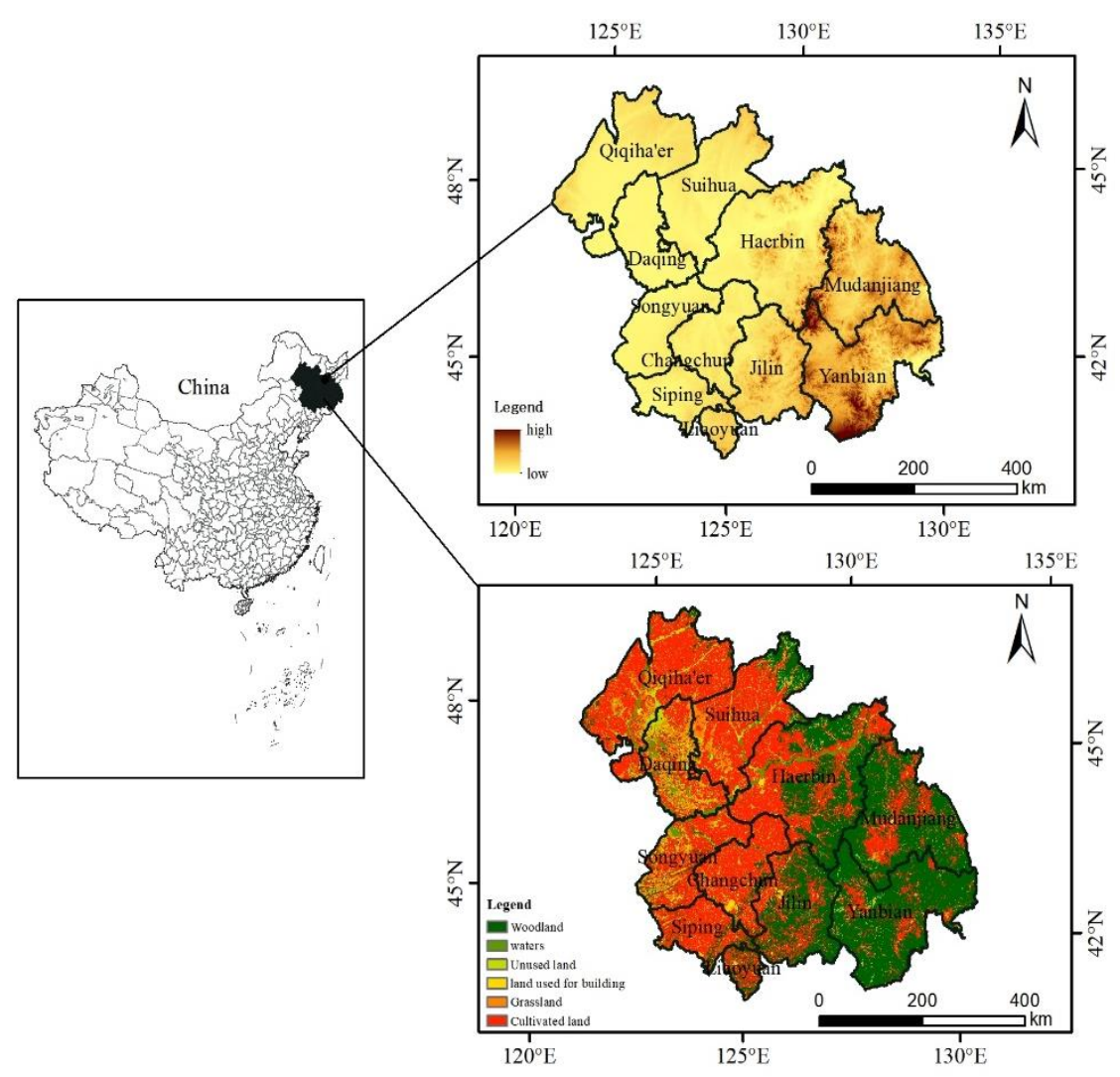

Figure 1. Map of the study area.

\subsection{Methods}

\subsubsection{Indicator System of Urbanization}

Urbanization is a complex system. Current studies generally consider urbanization to include four levels: population, land, economic, and social urbanization [39]. From the perspective of planning and practice, we should focus on the coordination between population and land urbanization. Population urbanization is the proportion of urban population in the total urban land and is the core of urbanization. Land urbanization refers to the proportion of built-up area in the total urban land; it is the carrier of urbanization [43]. Under the profound influence of the traditional household registration system, the population urbanization pattern of China is significantly different from that of other developing countries and developed countries. As a basic management system in Chinese society, the household registration system is closely related to resource allocation and benefit distribution [44]. The dual household registration system limits the free flow of the agricultural surplus population. The discrimination of household registration makes the floating population unable to enjoy the same social security and public service as the citizens, thereby limiting urban labor resources, and continually affects the urbanization [41].

Therefore, we distinguish the urbanization rate from the level of urban development and analyze the coordinated development degree of urbanization from the above two aspects. The population urbanization rate is the proportion of non-agricultural population in the total population, whereas land urbanization rate is a proportion of the built-up area to administrative area. The urbanization rate of population and land can only indicate the urban population (indicates the transfer rate of the agricultural population to non-agricultural) and land growth rate but not the urbanization quality of population and land. The coordination of population and land urbanization rate is an important means to express the quality of population and land urbanization. It is an index to evaluate the level of urbanization development [43]. 
Therefore, to explain the development level of population and land urbanization, we select 11 indicators from the five aspects of population size (proportion of non-agricultural population, proportion of employees in secondary and tertiary industries), economic life (per capita disposable income of urban residents, average wage of on-the-job workers), cultural environment (per capita public library collection, college students per 10,000), ecological environment (per capita green space area, urban per capita public green space area) and public service (per capita road area, number of doctors per 10,000 people, buses per 10,000 people) to build an evaluation index system. The evaluation index system of land urbanization is established from two parts, namely, land input (the proportion of built-up land area, per capita built-up land area, green coverage area of built-up area, greening coverage in built-up areas, land-average fixed assets investment) and land output (land-average gross domestic product (GDP), land-average fiscal revenue, land-average retail sales of consumer goods), which include eight indicators. In accordance with availability, scientific and comprehensiveness of index selection, the evaluation system of the two indexes is determined. Range analysis is performed to standardize the original data of variables, and then the entropy weight method is used to determine the weight coefficient of each index (Table 2), as stated in the following section.

Table 2. The quality of population and land urbanization evaluation index-system.

\begin{tabular}{|c|c|c|c|c|}
\hline $\begin{array}{c}\text { System } \\
\text { Level }\end{array}$ & $\begin{array}{l}\text { Element } \\
\text { Level }\end{array}$ & Weight & Indicator & Weight \\
\hline \multirow{9}{*}{ 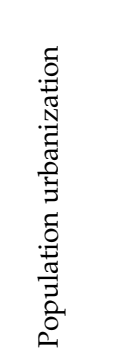 } & \multirow{2}{*}{$\begin{array}{l}\text { Population } \\
\text { size }\end{array}$} & \multirow{2}{*}{0.06} & Proportion of non-agricultural population (\%) & 0.03 \\
\hline & & & The proportion of employees in secondary and tertiary industries (\%) & 0.03 \\
\hline & \multirow{2}{*}{$\begin{array}{l}\text { Economic } \\
\quad \text { life }\end{array}$} & \multirow{2}{*}{0.10} & Per capita disposable income of urban residents (RMB) & 0.05 \\
\hline & & & Average wage of on-the-job workers (RMB) & 0.05 \\
\hline & \multirow{3}{*}{$\begin{array}{l}\text { Public } \\
\text { service }\end{array}$} & \multirow{3}{*}{0.16} & Per capita Road area (square meters) & 0.05 \\
\hline & & & Number of doctors per 10,000 people & 0.04 \\
\hline & & & Buses per 10,000 people (cars) & 0.06 \\
\hline & \multirow{2}{*}{ Cultural life } & \multirow{2}{*}{0.07} & Per capita public library collection (books, pieces) & 0.04 \\
\hline & & & College students per 10,000 & 0.03 \\
\hline & \multirow{2}{*}{$\begin{array}{l}\text { Ecological } \\
\text { environment }\end{array}$} & \multirow{2}{*}{0.11} & Per capita green space area (square meters) & 0.07 \\
\hline & & & Urban per capita public green space area (square meters) & 0.05 \\
\hline \multirow{8}{*}{ 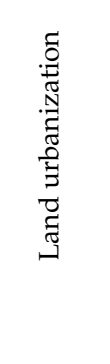 } & \multirow{5}{*}{ Land input } & \multirow{5}{*}{0.29} & The proportion of built-up land area (\%) & 0.07 \\
\hline & & & Per capita built-up land area (square kilometers) & 0.04 \\
\hline & & & Green coverage area of built-up area (hectare) & 0.06 \\
\hline & & & Greening coverage in built-up areas (\%) & 0.05 \\
\hline & & & $\begin{array}{l}\text { Land-average fixed assets investment (ten thousand RMB/thousand } \\
\text { square meters) }\end{array}$ & 0.07 \\
\hline & \multirow{3}{*}{$\begin{array}{l}\text { Land } \\
\text { output }\end{array}$} & \multirow{3}{*}{0.21} & Land-average GDP (ten thousand RMB/thousand square meters) & 0.06 \\
\hline & & & Land-average fiscal revenue (ten thousand RMB/thousand square meters) & 0.08 \\
\hline & & & $\begin{array}{l}\text { Land-average retail sales of consumer goods (ten thousand } \\
\text { RMB/thousand square meters) }\end{array}$ & 0.07 \\
\hline
\end{tabular}

\subsubsection{Development of the Entropy Weight Model}

The entropy weight method is a relatively objective weight method, which is widely used in the field of the social economy $[45,46]$. We use the entropy weight method to account for the weight of 11 indicators of population urbanization and eight indicators of land urbanization $W_{i j}$.

First, we standardize the original data of selected indicators $Y=y_{i j}$.

The indicators can be a positive or negative indicator. The positive indicator refers to the change in strength relative index value similar to the change in the urban development level. In other words, the greater the value, the higher the level of development. The negative indicator means that the change in a relative index value of strength is contrary to the urban development level. In other words, the smaller the value, the higher the level of development. The standardized method of positive and negative indicators is as follows: 


$$
\begin{aligned}
y_{i j} & =\frac{x_{i j}-\min _{i j}}{\operatorname{maxx}_{i j}-\min _{i j}} \text { (Positive indicator), } \\
y_{i j} & =\frac{\operatorname{maxx}_{i j}-x_{i j}}{\operatorname{maxx}_{i j}-\min _{i j}} \text { (Negative indicator), }
\end{aligned}
$$

where $y_{i j}$ represents the value of the standardization index, and $x_{i j}$ represents urbanization evaluation index.

Second, we determine the entropy of the indicators:

$$
E=-K \sum_{i=1}^{k} P_{i j} \ln P_{i j} K=1 / \ln (k) .
$$

Third, we calculate the weight of the indicator:

$$
W_{j}=\left(1-E_{j}\right) / \sum\left(1-E_{j}\right) .
$$

Table 2 shows the weights of various indicators of population and land urbanization calculated by the entropy weight method. We express the development level of population urbanization from five levels. The weight of public service and ecological environment indicators is relatively high. The ratio of land input and land output under the indicators of land urbanization is close to 1 . The construction of the indicator system and the weight ratio are consistent with the current people-centered, new-type, and intensive urbanization goals, which emphasize the improvement of the quality of urbanization.

\subsubsection{Modeling}

We utilize the coordination model to evaluate the coordination of population and land urbanization rate and the comprehensive development level of population and land urbanization.

\section{Coupled Coordination Model of Population and Land Urbanization Rate}

Normally, a growth disparity can be observed between population and land urbanization. Hence, the growth of the non-agricultural population and built-up area is non-synchronously. The rate gap between population and land urbanization is an inevitable problem in economic and social development and an objective law of economic and social development. As long as the gap between the growth of the non-agricultural population and the built-up area is within a certain range, the economy and society will continue to develop. This urbanization model is also recognized [47]. Following this idea, we cite the model used by the predecessors to analyze the rate coordination of population and land urbanization and the coordination degree between population and land urbanization [43,48]:

Calculation Formula of the Rate of Population and Land Urbanization

$$
\begin{aligned}
& A=\frac{A_{n+1}-A_{n}}{A_{n}}, \\
& P=\frac{P_{n+1}-P_{n}}{P_{n}} .
\end{aligned}
$$

Formula (5) expresses the growth of land urbanization in urban. $A_{n}$ and $A_{n+1}$ are the built-up areas in the $n_{\text {th }}$ and $(n+1)$ th year.

Formula (6) expresses the growth of the non-agricultural population in urban. $P_{n}$ and $P_{n+1}$ are non-agricultural population in the $n_{t h}$ and $(n+1)_{t h}$ year. 
Calculation Model of Coordinated Degree of Population and Land Urbanization Rate

$$
R=\frac{|A+P|}{\sqrt{2\left(A^{2}+P^{2}\right)}}
$$

Model (7) is the coupling degree of population and land urbanization rate [47,49].

In accordance with the coupling index, the coupling degree between the land and population urbanization rate can be divided into three categories (Table 3):

Table 3. The coordination type of population and land urbanization rate.

\begin{tabular}{cccc}
\hline R & Coordination Type & $\begin{array}{c}\text { The Relationship } \\
\text { between P and A }\end{array}$ & Characteristics \\
\hline $0 \leq \mathrm{R} \leq 0.8$ & Uncoordinated & $\begin{array}{l}\mathrm{P}>\mathrm{A} \\
\mathrm{P}<\mathrm{A}\end{array}$ & $\begin{array}{c}\text { Land urbanization lags behind } \\
\text { Population urbanization lags behind }\end{array}$ \\
\hline \multirow{2}{*}{$0.8<\mathrm{R} \leq 0.9$} & Basically coordinated & $\begin{array}{l}\mathrm{P}>\mathrm{A} \\
\mathrm{P}<\mathrm{A}\end{array}$ & $\begin{array}{c}\text { Land urbanization lags behind } \\
\text { Population urbanization lags behind }\end{array}$ \\
\hline \multirow{2}{*}{$0.9<\mathrm{R}<1$} & Highly coordinated & $\begin{array}{l}\mathrm{P}>\mathrm{A} \\
\mathrm{P}<\mathrm{A}\end{array}$ & $\begin{array}{c}\text { Land urbanization lags behind } \\
\text { Population urbanization lags behind }\end{array}$ \\
\hline
\end{tabular}

Coupled Coordination Model of Population and Land Urbanization Comprehensive Level

Coupling is a concept of physics that refers to the phenomenon that two or more systems interact in motion and affect each other [50]. Population and land urbanization are the interdependencies of urbanization. They are the subsystems that coordinate and accelerate each other. They are also subsystems of urbanization that depend on each other and coordinate and promote each other's development.

The coupling degree between population and land urbanization is the degree of interaction between these two subsystems. Based on the concept, model and results of previous coupling research in physics $[43,51,52]$, we analyze the coupling coordination degree between population urbanization and land urbanization of the Ha-Chang urban agglomeration.

Comprehensive Level's Coupled Coordination Model

$$
\begin{gathered}
C=\left\{f(x) * g(y) /[f(x)+g(y) / 2]^{2}\right\}^{1 / 2}, \\
f(x)=\sum_{i=1}^{n} a_{i} x_{i} \\
g(y)=\sum_{i=1}^{m} b_{i} y_{i} \\
T=\alpha * f(x)+\beta * g(y) \\
D=\sqrt{C * T} .
\end{gathered}
$$

Equation (8) is a model to calculate coupling between the comprehensive level of population and land urbanization, where $f(x)$ and $g(y)$ are presented the individual subsystem level of population and land urbanization, respectively, and $a_{i}$ and $b_{i}$ are the weights of population and land urbanization as a subsystem of urbanization.

Equation (9) is built for calculating the comprehensive level of urbanization, given that urbanization has two subsystems. The population and land urbanization systems are assumed to be equally important. Therefore, the value of $\alpha$ and $\beta$ are 0.5, respectively. Formulas (8) and (9) represent the coupling degree and the comprehensive level of development of urbanization, respectively. Model (10) used to calculate the coordinated development between the overall development level of population and land urbanization systems. 
The classification method of comprehensive level coordination degree between population and land urbanization is generally adopted (as shown in Table 4). Coordination index 1 is the best. It is then divided into two stages and six types.

Table 4. Classification of coordinated development of population and land urbanization.

\begin{tabular}{cccc}
\hline Classification & Index Value & Classification & Index Value \\
\hline Serious maladjustment & $0 \leq \mathrm{D} \leq 0.2$ & Initial coordination & $0.6 \leq \mathrm{D}<0.7$ \\
Moderate maladjustment & $0.2 \leq \mathrm{D}<0.4$ & Moderate coordination & $0.7 \leq \mathrm{D}<0.8$ \\
Low maladjustment & $0.4 \leq \mathrm{D}<0.6$ & Highly coordinated & $0.8 \leq \mathrm{D} \leq 1$ \\
\hline
\end{tabular}

\section{Results}

\subsection{Coordination Degree of Population and Land Urbanization Rate}

The coordination of population and land urbanization rate refers to the coordination between the relative growth rate of the non-agricultural population and built-up area. Table 5 shows the coordination degree between population and land urbanization rates of the ten core cities in the Ha-Chang urban agglomeration. From 2000 to 2014, the coordination degree of growth of the non-agricultural population and built-up area is declined from 1 to 0.72 . According to the research on the coordination type of population and land urbanization rate, the rate of non-agricultural population and the built-up area of Ha-Chang urban agglomeration is in an overall imbalance [49].

From 2000 to 2007, the rate of population and land urbanization in Ha-Chang urban agglomeration is coordinated. Figure 2 shows the coordination degree of population and land urbanization growth. As shown in the figure, since 2000, the growth of the built-up area is generally higher than that of the growth of the non-agricultural population. The growth rate of both is unstable, whereas the rate of population urbanization is increased steadily and then decreased. In 2000-2008, although the growth rate of two subsystems of population and land urbanization is fluctuating and sharply increased. In 2009-2014, population urbanization enters a slow growth stage, whereas land urbanization is still in rapidly increasing, and the trend of land urbanization rate is U shaped. Overall, in 2000-2014, the growth of the population urbanization rate lags behinds that of the land urbanization rate. The urbanization of the Ha-Chang urban agglomeration is in the population lag type. 
Table 5. The coordinated degree of population and land urbanization rate from 2000 to 2014 in Ha-Chang urban agglomeration.

\begin{tabular}{cccccccccccccccc}
\hline & $\mathbf{2 0 0 0}$ & $\mathbf{2 0 0 1}$ & $\mathbf{2 0 0 2}$ & $\mathbf{2 0 0 3}$ & $\mathbf{2 0 0 4}$ & $\mathbf{2 0 0 5}$ & $\mathbf{2 0 0 6}$ & $\mathbf{2 0 0 7}$ & $\mathbf{2 0 0 8}$ & $\mathbf{2 0 0 9}$ & $\mathbf{2 0 1 0}$ & $\mathbf{2 0 1 1}$ & $\mathbf{2 0 1 2}$ & $\mathbf{2 0 1 3}$ & $\mathbf{2 0 1 4}$ \\
\hline Changchun & 1.00 & 0.99 & 1.00 & 0.94 & 0.81 & 0.80 & 0.80 & 0.83 & 0.68 & 0.81 & 0.72 & 0.78 & 0.69 & 0.74 & 0.82 \\
Jilin & 0.90 & 0.71 & 0.68 & 0.73 & 0.77 & 0.71 & 0.71 & 0.71 & 0.96 & 0.37 & 0.71 & 0.71 & 0.71 & 0.67 & 0.70 \\
Siping & 0.89 & 0.71 & 0.71 & 0.84 & 0.71 & 0.71 & 0.71 & 0.71 & 0.76 & 0.71 & 0.72 & 0.71 & 0.63 & 0.71 & 0.54 \\
Liaoyuan & 0.71 & 0.69 & 0.80 & 0.71 & 0.67 & 0.80 & 0.65 & 0.66 & 0.71 & 0.75 & 0.72 & 0.71 & 0.71 & 0.71 & 0.71 \\
Songyuan & 0.74 & 0.71 & 0.71 & 0.71 & 0.85 & 0.70 & 0.99 & 0.71 & 0.71 & 0.81 & 0.98 & 0.91 & 0.69 & 0.07 & 0.71 \\
Haerbin & 1.00 & 0.74 & 0.97 & 0.86 & 0.88 & 0.95 & 1.00 & 0.97 & 0.53 & 0.59 & 0.56 & 0.68 & 0.74 & 0.86 & 0.84 \\
Qiqiha'er & 0.71 & 0.72 & 0.71 & 0.71 & 0.71 & 0.67 & 0.67 & 0.71 & 0.70 & 0.71 & 0.71 & 0.60 & 0.71 & 0.71 & 0.71 \\
Daqing & 0.97 & 0.71 & 0.89 & 0.71 & 0.99 & 0.77 & 0.31 & 0.94 & 0.71 & 0.76 & 0.71 & 0.85 & 0.90 & 0.87 & 0.96 \\
Mudanjiang & 0.97 & 0.71 & 0.71 & 0.71 & 0.58 & 0.71 & 0.79 & 0.93 & 0.91 & 0.71 & 0.74 & 0.67 & 0.68 & 0.75 & 0.34 \\
Suihua & 0.54 & 0.71 & 0.71 & 0.71 & 0.71 & 0.71 & 0.70 & 0.71 & 0.71 & 0.71 & 0.71 & 0.71 & 0.71 & 0.66 & 0.71 \\
Total & 1.00 & 0.79 & 0.74 & 0.87 & 0.89 & 0.83 & 0.95 & 0.93 & 0.76 & 0.76 & 0.71 & 0.73 & 0.71 & 0.71 & 0.72 \\
\hline
\end{tabular}




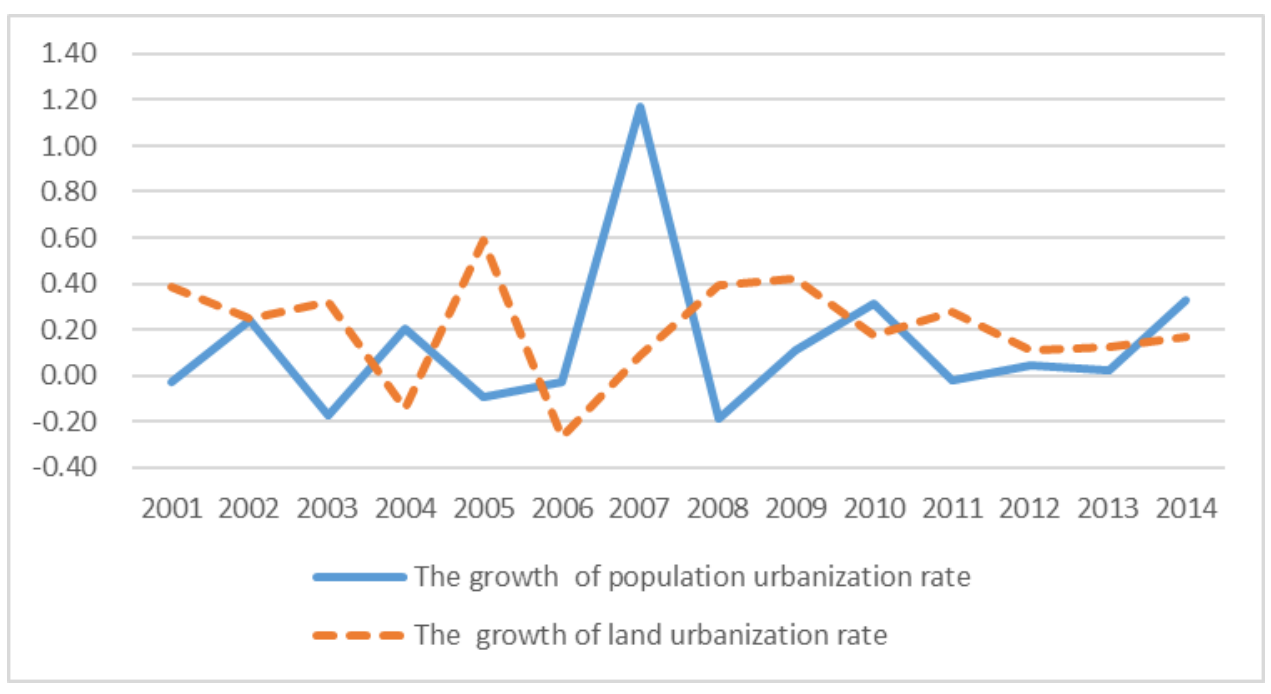

Figure 2. The rate of population urbanization and land urbanization from 2000 to 2014.

In accordance with the analysis of spatial features (shown Table 5), Daqing City ranks first in the coordination of population and land urbanization growth rate, and the coordination degree is 0.96 in 2014. Apart from Daqing City, only Changchun City and Haerbin City population and land urbanization rates are basically coordinated. All other cities are out of coordination, and the coordination degree of Mudanjiang City is the lowest at 0.33 .

Perfect urban infrastructure, high-quality social services, and high-level social security are important factors to eliminate or reduce the unfairness brought about by the dual structure of urban and rural areas. A high level of economic development can increase the input of population and land urbanization to perfect urban infrastructure, improve the quality of social services, and increase the investment of social security.

Large-sized cities have strong resource allocation rights, perfect urban supporting facilities, and strong population attraction which due to the strong agglomeration effect. Hence, they are gathering an increasing amount of population and resources to improve economic development. Therefore, naming Changchun City and Haerbin City as large-sized cities, the urbanization investment is higher than in other cities. Consequently, the population and land urbanization rate are better coordinated than in other cities. The coordinated index is 0.82 and 0.84 , respectively.

Natural environment conditions are the basis of urbanization. A good natural environment is conducive to urban population size and land expansion. Conversely, the poor natural environment also affects the development of urbanization. Mudanjiang City is located in the middle east of the Ha-Chang urban agglomeration. In this location, low hilly areas are difficult to exploit, the level of economic development is not high, the construction of urban public facilities is imperfect, and the effect of urban agglomeration is insignificant.

In accordance with the above empirical results, the coordination between population urbanization rate and a land urbanization rate of the Ha-Chang urban agglomeration in recent years shows a decreasing trend. The coordination of large-sized cities, such as Haerbin and Changchun City, is better than that of small and medium-sized cities. This good coordination is directly related to the high level of economic development of large-sized cities.

Heterogeneity among cities may be due to the difference in the socioeconomic levels of cities. The industrial structure is an important driving force for urban development. The added value of secondary and tertiary industries in Daqing City is close to $90 \%$ of GDP, which has a positive impact on the urban population concentration [53]. In Changchun City, Haerbin City, and Daqing City, the three cities with the highest wage levels of on-the-job workers, high wage levels increase the income gap between urban and rural residents and attract non-agricultural population to work in cities. 


\subsection{Analysis of Coordination of Population and Land Urbanization Comprehensive Level}

\subsubsection{Evaluation of the Comprehensive Level of Population and Land Urbanization}

The population and land urbanization level of the Ha-Chang urban agglomeration in 2000-2014 generally shows an upward trend. However, the level of comprehensive development is still not high. As shown in Table 5, the urbanization of the population is increased from 0.18 in 2000 to 0.69 in 2014. In accordance with the category of urban scale on Notice on Adjusting the Standard of Urban Scale issued in 2014 by the State Council, the Ha-Chang urban agglomeration includes three categories and four grades of cities in the classification of large-, medium- and small-sized cities. As the central cities, permanent residents in Harbin and Changchun City, which belongs to the first type (I) of large-sized cities, exceed 5 million. Between 2000-2014, Harbin urbanization level is increased from 0.45 to 0.61 , whereas the Changchun City urbanization level is increased from 0.26 to 0.82 , with an average annual growth rate of $2 \%$ and $9 \%$, respectively.

The urbanization level of population in Changchun City and Haerbin City is divided into three stages: during 2000-2002, Haerbin City and Changchun City population urbanization index is stable and with slow growth; from 2003 to 2007, the population urbanization index values of the two cities are fluctuating and declining to an extent; in 2008, Haerbin City and Changchun City, the population urbanization index is increased rapidly, and the function of public services and social environment for the population urbanization level is increased annually. The contribution rate of non-agricultural and industrial population structure to the urbanization level is lower than that of public services. Therefore, individual population agglomeration cannot reflect the urbanization level.

The second type (II) large-sized cities include Jilin City, Daqing City, and Qiqiha'er City. Their growth of population urbanization development level index is faster than other cities, which is $13 \%$, $16 \%$, and $10 \%$, respectively. The urbanization level of Jilin City and Daqing City is the highest at over 90\%. However, the urbanization level of Qiqiha'er City is the lowest among the core ten cities. Qiqiha'er is the second largest city in Heilongjiang Province. However, the slowdown of industrial development in recent years has led to a decrease in the attraction of cities for the rural surplus labor force. The decrease of the non-agricultural population ratio is $0.25 \%$, and the population urbanization index level is decreased by $42 \%$. Since the promulgation of the "Chang-Ji-Tu Space Development Strategic Plan", the investment in infrastructure has been increased, the public service and environmental quality have been improved, the urban agglomeration effect has been strengthened, the economic level has been improved, and the cities of Changchun City and Jilin City have been promoted. Siping City, Songyuan City, Mudanjiang City, and Suihua City are medium-sized cities, Siping City is an important city on the axis of Harbin-Daqing City, and its development is influenced by the radiation of Changchun City and Jilin City. Mudanjiang City is a resource-exhausted medium-sized city; the proportion of value-added in the tertiary industry accounts for $58.2 \%$ of GDP, hence, the tertiary industry develops rapidly, and the industrial transformation is successful. Although the population urbanization index level is generally rising in fluctuation, the urbanization level of small-sized cities is relatively lagging behind.

In view of the land urbanization development index, the levels of land urbanization in large-, medium- and small-sized cities in Ha-Chang urban agglomeration are rising steadily. Moreover, the growth rate is relatively stable, from 0.14 to 0.86 , with an average annual growth rate of $18.4 \%$. The proportion of land urbanization level is 8 percentage points higher than the level of population urbanization.

The development of land urbanization level in Ha-Chang urban agglomeration can be divided into two stages (Figure 3 shows). From 2000-2008, urbanization is guided by population urbanization, and the level of urbanization is based on the proportion of the non-agricultural population. All regions mainly focus to increase the urbanization level of the population. The urbanization of land is dominated by low input and low output, and the urbanization of land is stable at a low level. The urbanization level of population and land is increased from 0.18 and 0.08 in 2000 to 0.34 and 0.31 in 2008. Overall, the urbanization level of the population is generally higher than that level of land urbanization. 


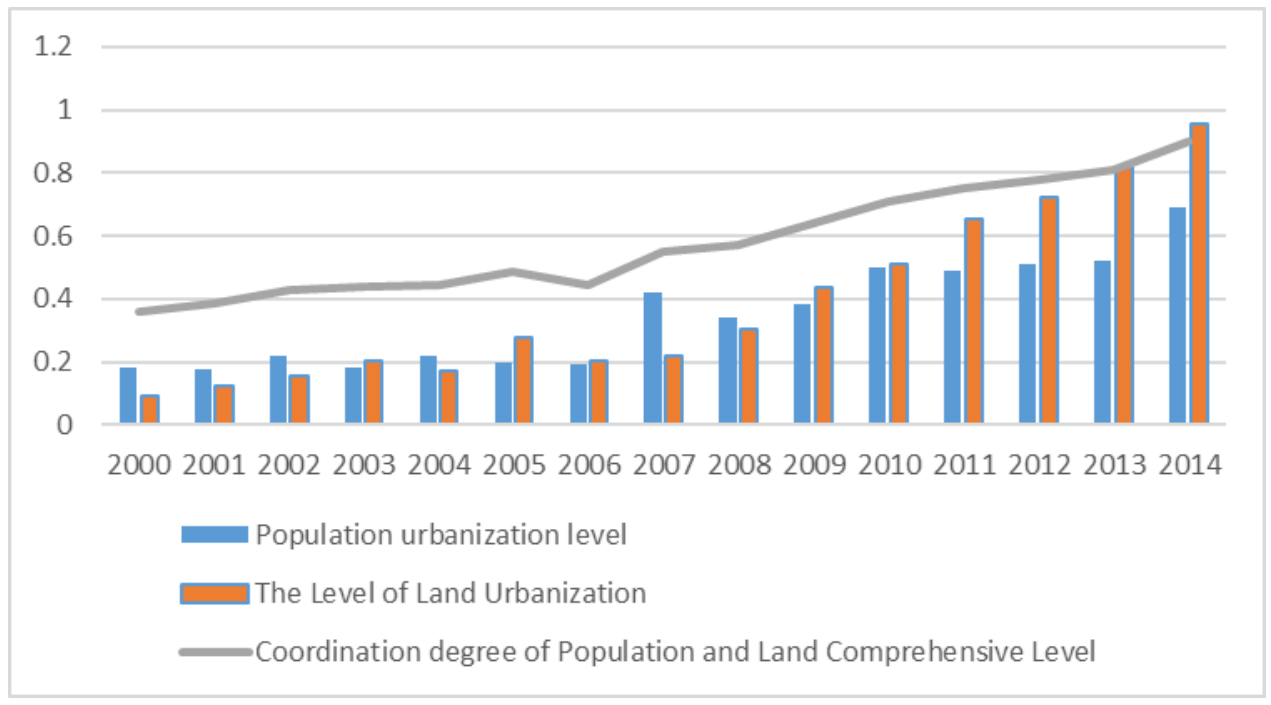

Figure 3. The coordination relationship with population and land urbanization quality from 2000 to 2014 .

The financial crisis in 2008 had a serious impact on the national economy, which is dependent on investment and export, that is, the space to drive the economy through external demand is becoming further small and more complicated. In this context, expanding domestic demand and increasing employment have become important driving forces and economic strategies to ensure the realization of the goal of maintaining growth. Urbanization is an important strategic choice to balance urban and rural development, increase employment opportunities for rural migrants, expand consumption and investment demand, break the dual economic structure, focus on long-term development and handle the financial crisis. In addition, for the regions' economic development, the role of land finance is further strengthened. Local governments have increased investment in land development and utilization. In addition to the economic crisis, the population growth of the urban is another factor driving the development of land urbanization. Under the early population-oriented urbanization development strategy, a large-scale population has gathered in the city. However, the backward urban public services and living environment cannot meet the needs of the large-scale urban population. Therefore, the level of land urbanization has increased yearly after 2009, thereby surpassing the level of population urbanization.

Meanwhile, regional economic development strategy plays an important role in urbanization. The social-economic development of the northeast area supported by policy to revitalize the old industrial base, increases the input of land urbanization. The built-up area of the Ha-Chang urban agglomeration is expanded by 927 square kilometers, with an average annual growth rate of $5.34 \%$, which is 4 percentage points higher than the average annual growth rate of the non-agricultural population. Compared with 2000, the built-up areas of large-sized cities, such as Changchun City, Haerbin City and Jilin City are increased by 311, 233, and 250 square kilometers, respectively. The average annual growth rates are $8.05 \%, 6.41 \%$, and $6.38 \%$. The average annual growth rate of built-up areas of Qiqiha'er City is the lowest among the ten core cities. Among medium-sized cities, Songyuan City's land urbanization level growth is more than 4 . However, the land urbanization level growth of Siping City, Mudanjiang City and Suihua City are not high, and that of Liaoyuan City which is a small city, is $3.1 \%$.

In accordance with the spatial characteristic analysis of the land urbanization level in Ha-Chang urban agglomeration, the level of land urbanization in 2014 is characterized as low in the western, central, and eastern regions. Changchun City and Songyuan City have the highest level of land urbanization, whereas Haerbin City and Mudanjiang City are lower than the average of urban 
agglomeration. The land utilization rate of Changchun City, Jilin, Songyuan City, and Qiqiha'er City, is high, about 90\%, whereas Siping City, Liaoyuan City, and Daqing City is in the middle, more than $80 \%$.

On basis of the analysis, the differences in urbanization level not only exist between different urban scales. The gap between same-sized cities is also relatively large. In accordance with the weights of different indicators, the transformation of industrial structure in large-sized cities is slow, and the contribution of urban public services and human settlements for population urbanization is increased significantly. The urbanization of the population between large-, medium-, and small-sized cities is not coordinated, and the radiation driving capacity of the center cities is weak.

\subsubsection{Coordination Results between Population and the Land Urbanization Comprehensive Level}

The coupling degree comprehensive level of population and land urbanization in Ha-Chang urban agglomeration is not bad, as shown in Table 6. However, the coupling degree cannot directly reflect the coordination degree between the two systems. When population and land urbanization levels are low, low levels of high coupling will also appear. On the contrary, the development of the two systems is better, and the level of development is higher. A high level of coupling occurs. If the population and land urbanization development level appear "high-low" or "low-high" matching, then the coupling degree will be significantly reduced.

Coordination is an integrated and ideal development level between population and land urbanization system, that is, a process of balanced regional development. The degree of coordination is a comprehensive reflection of the degree of harmony between population and land urbanization subsystem urbanization.

From the time dimension, the coordination degree between population and land urbanization of the ten core cities in the Ha-Chang urban agglomeration is improved, but it remains in imbalance. The coordination degree in 2009 is 0.63 , and the development trend is expected to be better.

On the basis of the model (shown in Table 7), the coupling coordination degree between population and land urbanization level in the Ha-Chang urban agglomeration is increasing yearly. The degree of coupling coordination between population and land urbanization level can be divided into two stages: 2000-2008, the stage of imbalance between population and land urbanization; 2009-2014, entering the coordination phase, the degree of coordination is rapidly increasing. 
Table 6. Coupling index of a comprehensive level of population and land urbanization from 2000 to 2014 in Ha-Chang urban agglomeration.

\begin{tabular}{cccccccccccccccc}
\hline & $\mathbf{2 0 0 0}$ & $\mathbf{2 0 0 1}$ & $\mathbf{2 0 0 2}$ & $\mathbf{2 0 0 3}$ & $\mathbf{2 0 0 4}$ & $\mathbf{2 0 0 5}$ & $\mathbf{2 0 0 6}$ & $\mathbf{2 0 0 7}$ & $\mathbf{2 0 0 8}$ & $\mathbf{2 0 0 9}$ & $\mathbf{2 0 1 0}$ & $\mathbf{2 0 1 1}$ & $\mathbf{2 0 1 2}$ & $\mathbf{2 0 1 3}$ & $\mathbf{2 0 1 4}$ \\
\hline Changchun & 0.019 & 0.168 & 0.138 & 0.824 & 0.624 & 0.998 & 0.926 & 0.988 & 0.945 & 0.956 & 0.980 & 0.975 & 0.968 & 0.948 & 0.965 \\
Jilin & 0.931 & 0.228 & 0.545 & 0.956 & 0.884 & 0.692 & 0.977 & 0.962 & 0.999 & 0.996 & 0.995 & 0.979 & 0.988 & 0.987 & 0.998 \\
Siping & 0.757 & 0.655 & 0.901 & 0.893 & 0.789 & 0.380 & 0.792 & 0.952 & 0.906 & 0.686 & 0.959 & 0.939 & 0.889 & 0.932 & 0.989 \\
Liaoyuan & 0.527 & 0.711 & 0.716 & 0.876 & 0.916 & 0.527 & 0.296 & 0.808 & 0.907 & 0.998 & 0.997 & 0.875 & 0.787 & 0.914 & 0.903 \\
Songyuan & 0.711 & 0.498 & 0.374 & 0.750 & 0.811 & 0.978 & 0.997 & 0.949 & 0.995 & 1.000 & 0.994 & 0.999 & 0.987 & 1.000 & 0.991 \\
Haerbin & 0.939 & 0.999 & 0.999 & 0.995 & 0.558 & 0.754 & 0.967 & 0.757 & 0.927 & 0.997 & 0.993 & 0.992 & 1.000 & 1.000 & 0.996 \\
Qiqiha'er & 0.904 & 0.527 & 0.989 & 0.686 & 0.824 & 0.928 & 0.890 & 0.661 & 0.996 & 0.996 & 0.965 & 0.836 & 0.918 & 0.688 & 0.567 \\
Daqing & 0.316 & 0.803 & 0.772 & 0.444 & 0.703 & 0.936 & 0.956 & 0.937 & 0.982 & 0.996 & 0.977 & 0.955 & 0.961 & 0.955 & 0.997 \\
Mudanjiang & 0.624 & 0.811 & 0.913 & 0.990 & 0.993 & 0.904 & 0.959 & 0.974 & 0.746 & 0.737 & 0.917 & 0.958 & 0.979 & 0.976 & 0.997 \\
Suihua & 0.973 & 0.024 & 0.149 & 0.817 & 0.939 & 0.750 & 0.952 & 0.711 & 0.696 & 0.849 & 0.849 & 0.881 & 0.784 & 0.761 & 0.985 \\
Total & 0.940 & 0.984 & 0.984 & 0.998 & 0.993 & 0.987 & 1.000 & 0.948 & 0.998 & 0.998 & 1.000 & 0.990 & 0.985 & 0.976 & 0.987 \\
\hline
\end{tabular}

Table 7. Coordination index of a comprehensive level of population and land urbanization from 2000 to 2014 in Ha-Chang urban agglomeration.

\begin{tabular}{|c|c|c|c|c|c|c|c|c|c|c|c|c|c|c|c|}
\hline & 2000 & 2001 & 2002 & 2003 & 2004 & 2005 & 2006 & 2007 & 2008 & 2009 & 2010 & 2011 & 2012 & 2013 & 2014 \\
\hline Changchun & 0.141 & 0.248 & 0.244 & 0.323 & 0.422 & 0.485 & 0.528 & 0.523 & 0.672 & 0.645 & 0.745 & 0.789 & 0.845 & 0.846 & 0.943 \\
\hline Jilin & 0.380 & 0.147 & 0.243 & 0.431 & 0.465 & 0.474 & 0.507 & 0.590 & 0.620 & 0.689 & 0.734 & 0.786 & 0.852 & 0.877 & 0.964 \\
\hline Siping & 0.343 & 0.407 & 0.487 & 0.476 & 0.471 & 0.356 & 0.306 & 0.363 & 0.552 & 0.576 & 0.581 & 0.623 & 0.666 & 0.715 & 0.922 \\
\hline Liaoyuan & 0.376 & 0.421 & 0.474 & 0.534 & 0.570 & 0.434 & 0.334 & 0.506 & 0.582 & 0.663 & 0.751 & 0.701 & 0.717 & 0.800 & 0.830 \\
\hline Songyuan & 0.243 & 0.188 & 0.214 & 0.287 & 0.374 & 0.517 & 0.600 & 0.655 & 0.734 & 0.689 & 0.706 & 0.768 & 0.828 & 0.897 & 0.959 \\
\hline Haerbin & 0.623 & 0.636 & 0.667 & 0.754 & 0.377 & 0.447 & 0.465 & 0.343 & 0.495 & 0.624 & 0.692 & 0.750 & 0.768 & 0.819 & 0.793 \\
\hline Qiqiha'er & 0.301 & 0.307 & 0.307 & 0.288 & 0.323 & 0.460 & 0.500 & 0.644 & 0.547 & 0.574 & 0.722 & 0.783 & 0.792 & 0.746 & 0.705 \\
\hline Daqing & 0.212 & 0.241 & 0.265 & 0.216 & 0.361 & 0.434 & 0.431 & 0.586 & 0.660 & 0.703 & 0.808 & 0.856 & 0.885 & 0.881 & 0.956 \\
\hline Mudanjiang & 0.377 & 0.374 & 0.437 & 0.551 & 0.595 & 0.601 & 0.581 & 0.655 & 0.584 & 0.678 & 0.627 & 0.724 & 0.780 & 0.835 & 0.854 \\
\hline Suihua & 0.486 & 0.145 & 0.224 & 0.285 & 0.278 & 0.287 & 0.363 & 0.421 & 0.461 & 0.547 & 0.607 & 0.692 & 0.675 & 0.781 & 0.937 \\
\hline Total & 0.358 & 0.385 & 0.429 & 0.439 & 0.442 & 0.485 & 0.445 & 0.551 & 0.569 & 0.638 & 0.711 & 0.753 & 0.780 & 0.808 & 0.902 \\
\hline
\end{tabular}


Before 2006, population urbanization is dominant, and the rate and level of population urbanization are higher than that of land urbanization. In 2006, the level of population urbanization is raised to be similar to that of land urbanization, but the degree of coordination between population and land urbanization level is reduced by four percentage points. Since the fourth session of the 11th National People's Congress proposed to improve the layout and form of urbanization and improve the quality of urbanization in 2011, Jilin Province and Heilongjiang Provinces have deepened the reform of the household registration system and gradually improved the public service system and infrastructure construction. Between 2009 and 2014, the level of land urbanization is gradually increased beyond the urbanization level of the population; furthermore, the gap between both of them is increased, and the coordination degree of urbanization is increased from 0.63 in 2009 to 0.9 in 2014 . The overall coordinated development of the agglomeration is increased from 0.36 to 0.90 in 2000-2014, and the comprehensive development level rises from 0.14 to 0.82 .

To sum up the analysis, the transferred non-agricultural populations in Jilin City which is the core city of the Ha-Chang urban agglomeration, reach $72 \%$ of the total urban population; the coordination degree in this city is the highest, reaching 0.96 in 2014. From 2000 to 2014, the built-up areas of core cities continue to expand, from 864 square kilometers in 2000 to 1791 square kilometers in 2014, an increase of 1.07 times in 15 years, and urban built-up land area accounts for $55.5 \%$ of the administrative land area. Among them, Jilin City ranks first in coordination degree (shown in Table 8). The level of population and land urbanization are the best in the core cities.

Table 8. The coordinated degree of population and land urbanization quality in Ha-Chang urban agglomeration $2014 *$.

\begin{tabular}{cccccc}
\hline City & $f(x)$ & $g(y)$ & C & T & D \\
\hline Jilin & 0.9546 & 0.9056 & 0.9997 & 0.9301 & 0.9643 \\
Songyuan & 0.8830 & 0.9655 & 0.9990 & 0.9242 & 0.9609 \\
Daqing & 0.9407 & 0.8902 & 0.9996 & 0.9155 & 0.9566 \\
Changchun & 0.8158 & 0.9945 & 0.9951 & 0.9051 & 0.9491 \\
Suihua & 0.8274 & 0.9372 & 0.9981 & 0.8823 & 0.9384 \\
Siping & 0.8955 & 0.8127 & 0.9988 & 0.8541 & 0.9236 \\
Mudanjiang & 0.7489 & 0.7115 & 0.9997 & 0.7302 & 0.8544 \\
Liyuan & 0.6064 & 0.8443 & 0.9865 & 0.7254 & 0.8459 \\
Haerbin & 0.6107 & 0.6509 & 0.9995 & 0.6308 & 0.7940 \\
Qiqiha'er & 0.4187 & 0.9050 & 0.9301 & 0.6618 & 0.7846 \\
Total & 0.6932 & 0.9536 & 0.9874 & 0.8234 & 0.9017 \\
\hline
\end{tabular}

* Note: where $f(x)$ denotes the quality of population urbanization; $g(x)$ denote the quality of land urbanization; $\mathrm{C}$ indicates the coupling degree of population and land urbanization quality; $\mathrm{T}$ indicates the comprehensive development of urbanization; and D indicates the coordinated degree of population and land urbanization quality.

The Strategy of Northeast Revitalization and development and opening up of Chang-Ji-Tu Pilot Zone Building provide new opportunities for promoting the urbanization of Jilin Province. The central region of Jilin Province has a high level of economic development, a core area of economic development, a relatively perfect infrastructure, better traffic conditions than the eastern and western regions, and significant advantages in economy, technology, resources and system to promote urbanization. Therefore, the three cities of Jilin Province are in the forefront.

Daqing City, which is among the five core cities in Heilongjiang Province, is at the forefront. It is a resource-based city, where enterprises have a strong ability to gather and attract foreign capital to create a good employment environment for the transferred population. Its urban per capita income is the highest in the core cities of the Ha-Chang urban agglomeration, with 25.5 square meters of road per capita in the forefront. The urbanization rate of the non-agriculture population and built-up area is higher than that of other cities. 
The old industrial and natural resources of Heilongiiang Province are the main driving force for urbanization. As the two major powers of industry and resources have entered a weak state in recent years, the ability to promote urbanization has gradually weakened [54].

The coordination degree of Haerbin City and Qiqiha'er City is the lowest in the moderate coordination stage among the core cities. Its value is 0.79 and 0.78 , the population urbanization level is 0.61 and 0.42 , and the land urbanization level is 0.9 and 0.65 , respectively. Although Haerbin City is one of the central cities of the Ha-Chang urban agglomeration and an important industrial city in the country, it is affected by over-centralized urban functions, weak industrial diffusion effect, confusion of functional areas, crowded traffic, environmental pollution and other metropolitan diseases [55]. Its population and economic agglomeration capacity are insufficiently strong, thereby restraining the urban development.

\section{Discussion}

Sustainable development of urbanization plays an important role in social and economic development. Thus, the realization of rapid, coordinated, and healthy urbanization must take sustainable development as a guide. As the important parts of urbanization, land and population urbanization's essence and ultimate objective are to realize human urbanization. Their coordinated development is the core issue of sustainable development of urbanization [21]. The urbanization of the Ha-Chang urban agglomeration is significant to the economic transformation and the promotion of international economic participation in Northeast China. However, the population and economy of this agglomeration, as the important internal systems of urbanization, are lagging behind. Furthermore, the structure is loose, and the radiating impact of the central city is insufficient. Its population and land urbanization co-ordination are in the rising stage of development.

Urbanization is a complex system. The entropy weight method based on the synthesis of multiple indicators can effectively alleviate the disadvantages of the subjective weighting evaluation of a single indicator. This method can reflect the spatiotemporal coupling characteristics of the population and land level in the research area well. The non-agricultural population of the Ha-Chang urban agglomeration accounts for 0.72 , and the population urbanization quality index is 0.69 by the multi-index comprehensive entropy weight method. The population is the core of urbanization, and its essence is the transfer of population economic activities. In traditional cognition, the proportion of the non-agricultural population is used to reflect population urbanization [56]. However, the single non-agricultural population index only displays the urbanization of the population scale. It cannot explain the quality of population urbanization. The population is an important driving force to accelerate urban landscape change, especially to expand built-up areas [14]. At present, the impact of the household registration system on population urbanization cannot be ignored. The population urbanization rate can be measured by the scale of the non-agricultural population, and the quality of population urbanization can be fully reflected by using five secondary indicators that are closely related to population urbanization, namely, population scale, industrial structure, public facilities, cultural life, and ecological environment.

The rate of land urbanization is the expansion rate of the built-up area, which is not equal to the quality of land urbanization. The rate of land urbanization does not represent the quality of land urbanization. Several studies about matching the level of land urbanization with other aspects of urbanization, namely, population, economic, and social urbanization, are available. Examining the degree of coordination between land and population urbanization and conducting a reasonable evaluation of the quality of urbanization is a basis for adjusting the internal coordination of urban, which is beneficial for comparing urbanization with other regions [57].

The rate of population and land urbanization of the Ha-Chang urban agglomeration is gradually out of balance, and the level of population and land urbanization is increasing in successive periods. In 2014, the coordination degree of the Ha-Chang urban agglomeration reaches 0.9, compared with the Yangtze River economic belt index, that is, 0.98 . Therefore, it still has room for improvement. 
Different from London's mature urban agglomerations, where population spreads from the center to the periphery [58], the population of the Ha-Chang urban agglomeration is still in the stage of concentration to large-sized cities because of limited regional reform and opening-up, low economic development level and social capital inflows, lack of talents and technology, and inefficient use of various resources [59].

In terms of spatial distribution, under the constraints of an economic level, the industrial structure and resource environment, the urbanization rates of population and land in small-sized cities are evidently imbalanced. Particularly, the urbanization rates of population and land of large- and medium-sized cities are better than those of small-sized cities. However, the function of central cities is weak, the competence of population agglomeration is not strong, and the radiation capacity and range for surrounding areas are small. The phenomenon of unbalanced development appears in different-sized cities in urban agglomeration. The growth of the non-agricultural population of large-sized cities has better coordination with build-up area expansion than that of small- and medium-sized cities, and the quality of population and land urbanization of center cities is not good. As Beijing-Tianjin-Hebei Urban Agglomerations, the Ha-Chang urban agglomeration faces the same problem, that is, not being able to radiate to surrounding cities effectively. The reason is that the income level of residents in large-sized cities is relatively high, and the level of urban hardware construction, such as transportation, medical treatment, education and cultural infrastructure construction, is better than that of small- and medium-sized cities. This result is because the core cities of large-, medium-, and small-sized cities in the urban agglomeration are independent and lacking overall development planning. Japan has been relatively successful in equilibrium development of large-, medium-, and small-sized cities [60]

Sustainable urban forms are the physical dimensions of socially desired urban and community physical forms [3]. However, the coordination can improve city planning which can enhance the city's ability to resist risks [61,62]. Thus, it is the key to sustainable urban forms and regional sustainable development [63]. As a regional urban agglomeration, Ha-Chang urban agglomeration plays an important role in the economic and social development of northeast China. Therefore, it should stick to the two approaches. On the one hand, the significant efforts should be made to develop urban agglomerations, give full play to the radiating role of megacities, and avoid excessive population expansion in large-sized cities. On the other hand, small- and medium-sized cities should be developed to increase the attractiveness of the migrant population, effectively reduce the cost of the urbanization development, and improve the efficiency of urbanization. Improving the attractiveness of small- and medium-sized cities is a major strategic choice for China's balanced urbanization. Developing small-sized cities is an indispensable strategic fulcrum of China's balanced urbanization, which is practically significant for promoting the healthy and sustainable development of China's new-type urbanization.

\section{Conclusions}

This paper used Ha-Chang urban agglomeration as the research area, applied the econometric model of time series to study the interaction between population and land urbanization of Ha-Chang urban agglomeration, and applied the coordinated development degree model to analyze and evaluate the coordination development of population and land urbanization. In addition, exploratory research is an important measure to reveal the condition of urbanization development and discover the spatial heterogeneity of coupling coordination degree on sustainable urbanization [64]. According to the results of this research, we found that the industrial base of small- and medium-sized cities is weak. On this basis, opportunities for career development are limited. Government financial constraints lead to evident disparities among large-sized cities in terms of urban infrastructure, basic public services, and housing security systems. Furthermore, the level of citizenization of the rural migrant population in urban is low. Small- and medium-sized cities are unattractive to the rural migrant population, and 
the coordination between population and land urbanization is weak. Such cities have not played their due role in urbanization.

The Ha-Chang urban agglomeration should improve the attractiveness of small- and medium-sized cities to the rural migrant population. Such improvement is the key to promoting the new urbanization of agglomeration. First, given that small- and medium-sized cities rely on their own advantages to form characteristic industrial clusters, which have regional influence, a stable employment environment. Second, vocational training for migrant workers should be strengthened for improving the ability of rural migrants to integrate into cities. Third, the problem of government funding bottlenecks should be solved by improving the financial support of small- and medium-sized cities, establishing public and private mechanisms, establishing good cooperative relations, attracting social capital to enter public service provision and infrastructure construction in small- and medium-sized cities, and improving public services such as medical care, pension services, and skills training, thereby improving the speed of urbanization and the quality of development.

Although we report several important findings, this study has some notable limitations. We analyze the coordination between population and land urbanization through two paths of rate and quality and find that the coordination degree between population and land urbanization rate is gradually reduced. On the contrary, the coordination of population and land urbanization quality is gradually enhancing. First, because the household registration system in China still affects urbanization, the population urbanization in this study uses a non-agricultural population; however, the non-agricultural population data are available only until 2014, thereby shortening the research period of the article. Second, the results of the coordination between population urbanization and land city rate and quality are reversed.

Future research can start from the following aspects. Given the factors affecting the population and land urbanization, the index system will be further improved, and the coordination between population and land urbanization rate and quality will be analyzed. From the perspective of urban development disparity, the impact of regional resource endowment and innovation on urbanization will also be analyzed, and the promotion of a human-centered urbanization development system will be proposed.

Author Contributions: Supervision, H.L.; Writing—original draft, H.H. All authors have read and agreed to the published version of the manuscript.

Funding: This research was funded by the National Social Science Foundation of China (No. 14BRK035).

Conflicts of Interest: The author declares no conflict of interest.

\section{References}

1. Li, C.; Li, P. Sustainable development of urban agglomeration in China: From concept to evaluation. J. Chongqing Univ. (Soc. Sci. Ed.) 2018, 24, 1-12.

2. Yao, S.; Chen, Z.; Zhu, Y. The Urban Agglomerations of China, 3rd ed.; University of Science and Technology of China Press: Beijing, China, 2006; p. 4.

3. Eizenberg, E.; Jabareen, Y. Social Sustainability: A New Conceptual Framework. Sustainability 2017, 9, 68. [CrossRef]

4. Zhang, Z. Study on Research Progress of the Mechanism of Urban Sprawl and Spatial Morphology Evolution. J. Chongqing Jiaotong Univ. (Nat. Sci.) 2008, 5, 826-830.

5. Yao, S. New Recognition on City Group Basic Concept. Urban Res. 1998, 6, 15-17.

6. Gu, S.; Cao, D.; Han, L. Transformation and development of urbanization in China during the 13th Five Year Plan period. China Popul. Resour. Environ. 2017, 4, 6-15.

7. Pyrgiotis, Y.N. Urban Net Working in Europe. Ekistics 1991, 50, 350-351.

8. Kunzmann, K.R.; Wegener, M. The Pattern of Urbanization in Western Europe. Ekistics 1991, 50, 156-178. 
9. Ni, P.; Hou, Q. Report about the Power of Urban Competition in China; Social Science Academic Press: Beijing, China, 2004; pp. 78-82.

10. Fang, C.; Song, J.; Zhang, M.; Li, M. The Formation, Development and Spatial Heterogeneity Patterns for the Structures System of Urban Agglomerations in China. Acta Geogr. Sinica 2005, 60, 827-840.

11. Wang, Q.; Fang, C. New-type driving forces of urban agglomerations development in China. Geogr. Res. 2011, 30, 335-347.

12. Wang, G. Features of Urbanization and Urban Agglomeration in Yangtze River Delta. Popul. Sci. China 2005, 2, 44-52, 97.

13. Deng, J.S.; Qiu, L.F.; Wang, K.; Yang, H.; Shi, Y.Y. An integrated analysis of urbanization-triggered cropland loss trajectory and implications for sustainable land management. Cities 2011, 28, 127-137. [CrossRef]

14. Krajewski, P.; Solecka, I.; Mrozik, K. Forest Landscape Change and Preliminary Study on Its Driving Forces in Ślęża Landscape Park (Southwestern Poland) in 1883-2013. Sustainability 2018, 10, 4526. [CrossRef]

15. Lai, X. Study on the coordinated development of population urbanization and land urbanization in China. Money China 2015, 9, 361-362.

16. Chen, C. Research on healthy development of urbanization. Territ. Nat. Resour. Study 2008, 4, 7-9.

17. Liu, J.; Zheng, Q.; Guo, R.; Li, M. Evaluation on Coordinate Development for Urbanization in Population and Land of Chongqing. J. Southwest China Norm. Univ. (Nat. Sci. Ed.) 2012, 37, 66-72.

18. Lu, D. Urbanization Process and Spatial Sprawl in China. Urban Plan. Forum 2007, 4, 47-52.

19. Zhang, W.; Zhang, Z. Problems of Land Expropriation System in Process of Urbanization and Countermeasures. Chin. Agric. Sci. Bull. 2009, 25, 271-276.

20. Li, Q. Self-examination and Self-criticism on China's Rural and Urban Development-Discussion on the New Form of Rural Areas and City during its Integration. J. Liaoning Norm. Univ. (Soc. Sci. Ed.) 2012, 35, 608-613.

21. Liu, X. Land Urbanization and Population Urbanization Coordinated Development Research of Henan Province. Master's Thesis, Zhengzhou University, Zhengzhou, China, 2015.

22. Michael, P. The internal structure of cities in the Third World. Geography 2001, 86, 189-209.

23. Tan, M.; Li, X.; Lv, C. An Analysis of Driving Forces of Urban Land Expansion in China. Econ. Geogr. 2003, 23, 635-639.

24. Zhou, H.; Wu, J. Industrialization, urbanization and government choice. Res. Dev. 2005, 1, 86-88.

25. Zhao, W.; Zhao, F.; Yang, F.; Li, L. Land Transfer, Reform of Household Registration System and Urbanization in China: Theoretical and Simulation Test. Econ. Res. J. 2017, 52, 183-197.

26. Jiang, Z.; Liu, J.; Han, F. Traffic Congestion, Spatial Spillovers and Population Urbanization in China. Collect. Essays Financ. Econ. 2019, 5, 104-112.

27. Wang, S.; Ma, Q. Land Management and Urbanization. China Land 2000, 1, 12-15.

28. Zhang, L.; Zhang, S. Land Resources and Urbanization. Resour. Sci. 2008, 4, 578-584.

29. Krajewski, P. Monitoring of Landscape Transformations within Landscape Parks in Poland in the 21st Century. Sustainability 2019, 11, 2410. [CrossRef]

30. Lv, P.; Zhou, T.; Zhang, Z.F.; Tian, Z. Construction and Application of Land Urbanization and Corresponding Measurement Index System. China Land Sci. 2008, 22, 24-28, 42.

31. Hubacek, K.; van den Bergh, J.C. Changing concepts of 'land' in economic theory: From single to multi-disciplinary approaches. Ecol. Econ. 2006, 56, 5-27. [CrossRef]

32. Peng, J.; Jiang, Y.; Li, Z. Evaluation of land use efficiency-A Case Study of Jiangning County. Resour. Environ. Yangtze Basin 2005, 3, 304-309.

33. Han, S.; Pu, L. Spatial Differentiation of Comprehensive Land use Efficiency in Jiangsu Province. Resour. Environ. Yangtze Basin 2008, 6, 853-859.

34. Guo, S.; Wang, F.; Gao, M. Spatial-Temporal Coupled Coordination between Population Urbanization and Land Urbanization in Shandong Peninsula. Econ. Geogr. 2014, 3, 72-78.

35. Yu, X.; Jun, Z.; Wu, Y. Why should We Build Population Balance Society. Popul. Res. 2010, 3, 40-52.

36. Shi, J.; Huang, Z.; He, C.; Wang, W. A Comprehensive Measurement of the Utility of Land Use of 16 City-Regions in China. Econ. Geogr. 2013, 2, 76-81.

37. Xing, X. Research on Land Finance Problem in Urbanization Perspective-Based on Data of Xinjiang Province. J. Harbin Univ. Commer. (Soc. Sci. Ed.) 2012, 1, 42-48. 
38. Tan, S.; Song, H. Matching Status of Land Urbanization and Population Urbanization. Urban Probl. 2013, 11, 2-6.

39. Yin, H.; Xu, T. The Mismatch between Population Urbanization and Land Urbanization in China. Urban Plan. Forum. 2013, 2, 10-15.

40. Liang, Q. Ministry of land and resources: Urbanization scale should be controlled by "land limit". Econ. Inf. Daily 2013, 04-01(001). Available online: http://dz.jjckb.cn/www/pages/webpage2009/html/2013-04/ 01/content_73043.htm?div=-1 (accessed on 25 December 2019).

41. Tan, C.; He, W. Hukou Discrimination, Urban System and Urbanization: A Theoretical and Empirical Study from the Perspective of New Economic Geography. Nankai Econ. Stud. 2019, 1, 46-65.

42. He, X.; Du, L. Research on the Formation and Development of the Formation and Development of the Harbin-Changchun City Group. J. Northeast. Norm. Univ. (Philos. and Soc. Sci.) 2016, 5, 123-130.

43. Chen, F.; Zhang, H.; Wu, Q. A Study on Coordinate Development between Population Urbanization and Land Urbanization in China. Hum. Geogr. 2010, 5, 53-58.

44. Ning, J.; Yan, J. Hukou Identity Change and Rural Migrant Workers' Sense of Justice under the Urbanization Process. Lanzhou Acad. J. 2018, 3, 185-196.

45. Guo, X. Application of Improved Entropy Method in Evaluation of Economic Result. Syst. Eng. Theory Pract. 1998, 12, 99-103.

46. Xu, Z.; Sun, Z. Priority method for a kind of multi-attribute decision-making problems. J. Manag. Sci. China 2002, 3, 35-39.

47. Zhu, F.; Zhang, F.; Li, C.; Jiao, P.; Wang, J. Coordination and Regional Difference of Urban Land Expansion and Demographic Urbanization in China during 1993-2008. Prog. Geogr. 2014, 5, 647-656.

48. Li, D.; Wang, Z.; Lan, X. Evaluation on Coordination Between Population Urbanization and Land Urbanization of Poyang Lake Agglomeration. Sci. Technol. Manag. Land Resour. 2016, 1, 16-23.

49. Fan, J.; Zhao, D.T. The Coordination Determination of Land Urbanization and Population Urbanization and Its Influencing Factors. Economist 2012, 5, 61-67.

50. Zhou, H. Modern Chinese Vocabulary; Guangming Daily Press: Beijing, China, 2003; pp. 820-821.

51. Luo, P.; Yan, X.; Wan, L. Study of Coordination of Population Urbanization with Land Urbanization in Harbin, a Cold Northern City. J. Glaciol. Geocryol 2017, 5, 1150-1156.

52. Li, Y.; Li, X.; Cai, Z. Coupling Coordination Relationship between Population Urbanization and Land Urbanization in Guiyang. Guizhou Sci. 2018, 2, 55-60.

53. Zhang, M.; Li, B. Research on Spatial-temporal Pattern and Its Influencing Factors of Talent Agglomeration in China. Sci. Technol. Prog. Policy 2018, 35, 38-44.

54. Wu, X. Research on the Development Path of Population Urbanization in Heilongjiang Province. Stat. Consult. 2013, 4, 8-10.

55. Liu, X.; Yang, Q.; Zhang, P. Research on Harbin Metropolis Circle's Development of Urbanization and Spatial Organization. Econ. Geogr. 2008, 1, 96-99.

56. Cao, W.L.; Zhang, X.L.; Pan, Y.Y.; Zhang, C. Coordinate Development among Population, Land and Economy Urbanization in Developed Area: The Case of Jiangsu Province. China Popul. Resour. Environ. 2012, 22, 141-146.

57. Lyu, Y.; Li, J. Evaluation of Land Urbanization and its Temporal and Spatial Characteristics of Urban Agglomeration Surrounding Poyang Lake area. Nat. Resour. Econ. China 2015, 28, 43-47, 62.

58. Mao, X.; Zhai, Z. Spatial Path of Urbanization in London Metropolitan and Its' Implications. Soc. Sci. Beijing 2013, 139-146.

59. Liao, Q.; Guo, H. Study on Coordination Development Quality of Guanzhong City Cluster. City House 2019, $26,41-44$.

60. Wang, L. Urbanization Process, Characteristics in Japan and Its Enlightenment to China. J. Anhui Agric. Sci. 2018, 15, 212-216.

61. Jabareen, Y. Conclusions. In The Risk City; Lecture Notes in Energy; Springer: Dordrecht, The Netherlands, 2015; Volume 29, pp. 197-204.

62. Jabareen, Y. A New Conceptual Framework for Sustainable Development. Environ. Dev. Sustain. 2008, 10, 179-192. [CrossRef] 
63. Liu, Y. Study on the coordination degree of regional economic sustainable development system. Soc. Sci. J. 2000, 5, 81-85.

64. Zhang, Y.; Su, Z.; Li, G.; Zhuo, Y.; Xu, Z. Spatial-Temporal Evolution of Sustainable Urbanization Development: A Perspective of the Coupling Coordination Development Based on Population, Industry, and Built-Up Land Spatial Agglomeration. Sustainability 2018, 10, 1766. [CrossRef] 